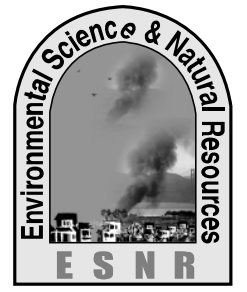

J. Environ. Sci. \& Natural Resources, 5(2): 339 - 344, 2012

ISSN 1999-7361

\title{
Jhum Cultivation Influence the Degradation of Hilly Environment
}

\author{
A. S. Chakma ${ }^{1}$ and B. S. Nahar ${ }^{2}$ \\ ${ }^{1}$ Department of Environmental Science and ${ }^{2}$ Center for Environmental Studies, Bangladesh Agricultural \\ University, Mymensingh
}

\begin{abstract}
This study was designed to identify the status of shifting (jhum) cultivation and its impact on environment in Rangamati district. A total 55 jhum cultivators were selected on the basis of purposive sampling technique from 5 upazillas of Rangamati district. Data were collected during the period October to December, 2009. The researcher collected information himself using direct and open questionnaire. The study revealed that most of the jhum cultivators were middle age (30-50 years), with illiterate (47.27\%) and main occupation possessing jhum cultivation. The present status of agricultural land (hill/slope) of jhumia family in the studied area, about $60 \%$ of the respondents have only 1-2 acres of land for jhum cultivation and $25 \%$ of the respondents have 2.1 3 acres of land. The use of agro-chemical remains limited in the CHT. This is mainly because of financial constraints, lack of market access, and low requirement of chemical for traditional jhum cultivation. The maximum percentage of irrigation (74.55\%) was mainly depended on rainfed in jhum cultivation. On the other hand about $45.55 \%$ respondents were responded that their income status were medium through shifting cultivation, $30.90 \%$ were responded high. Similarly in the study area it was found that a majority $(45.45 \%)$ portion of respondents were responded that labour utilization in shifting cultivation was medium. This study also found that the environment was degraded gradually day by day. The maximum respondents (94.55\%) had given opinion that deforestation was the major environmental problem created by shifting cultivation, $74.55 \%$ respondents had given opinion that shifting cultivation accelerated loss of top soil and $60.00 \%$ respondents had given opinion that lost of wild animals was occurring due to shifting cultivation. Biodiversity also degraded mostly. Excluding shifting cultivation there were many reasons of environmental degradation in the study area. Population growth is considered by $90 \%$ of the respondents as a major factor causing severe degradation of environment. Indiscriminate forest fire was responsible for environmental degradation. In addition cutting of hill, collection of soil, and extraction of stone, river erosion and land slide as responsible for degradation of environment. The study recommended that new methods must be developed, applied, and tested for sustainable management of jhum cultivation and environmental protection.
\end{abstract}

Key words: Jhum cultivation, degradation, hilly environment

\section{Introduction}

The Chittagong Hill Tracts (CHT) is located in southeastern of Bangladesh, bordering India and Myanmar. The total area of the Chittagong Hill Tract (CHT) is estimated at around 13,237 sq. km., which is about one tenth of the country. The area is hilly with mild to very steep slopes (from $15 \%$ to over $70 \%$ ) often breaking or ending in cliffs. More than 90 percent of the area is covered by hills with only 129,000 hectares (ha) of cropped land. About 87 per cent of the land is covered with forest (Totaling 11,475 sq. kms) mostly owned by the government (Dasgupta and Ahmed, 1998). Most of the valleys of the CHT area are covered with thick virgin forests. The main features of the vegetation are semievergreen (deciduous) or tropical evergreen, dominated by tall trees. Because of its geographical setting and the pristine nature of the CHT area, the potential of crop production from this region is not high; rather, a huge prospect for eco-tourism exists in the area. Thus the need for environmental conservation of natural forest lands of the CHT area is very important. Rangamati is the largest district of CHT. Its area is 6116.13 sq.km (BBS,2001). There are about 29 tribes in Bangladesh. Among them 12 tribes live in Rangamati. The main occupation of the tribes is mostly crop, livestock, horticulture and forestry agriculture. In ancient days the tribal people who lived in hilly areas used to practice shifting cultivation, which is ocally called jhum cultivation. It is a traditional crop cultivation system of the tribal hill people. Jhum cultivation is a special kind of agricultural practice on sloppy hills of the indigenous people of Chittagong Hill Tracts region. The method is also known as "Sweden" or "Slash and Burn" cultivation. Jhuming compromises cutting and burning of forest trees, clearing spaces and then sowing a variety of seeds. According to Banglapedia (2009) about 20,000 hectares of land are being brought under jhum cultivation every year.

Tripura and Harun (2003) carried out a survey to observe the dependency rate of community on jhum cultivation, past and present status of jhum cultivation, it alternatives, and socio-economic status of jhum cultivators. Gafur et al. (2003) conducted a research to find out the runoff and losses soil and nutrients from small watersheds under shifting cultivation (jhum) in the Chittagong Hill Tracts. Borggaard et al. (2003) carried out a study to analyze the sustainability appraisal of 
shifting cultivation in CHT. Dewan (2008) conducted a survey work to analyze the socioeconomic status of jhum cultivators.

Jhum cultivation influences land degradation, forest degradation, and biodiversity destruction in hilly region through deforestation and burning as a result the whole environment is destroyed.

Past research reports indicate that little work has been undertaken so far on soil erosion, biodiversity loss, deforestation, factors that contributing environmental degradation and impacts on environment due to shifting (jhum) cultivation practice. Keeping the above views in mind the present research work was undertaken to report in details with the following objectives.

$>$ To determine the extent of jhum cultivation practices by the jhumias;

$>$ To identify the factors which are contributing environmental degradation and

$>$ To observe the impacts of jhum cultivation on environment.

\section{Methodology}

\section{Site selection of the study area}

Within 64 districts of Bangladesh, Rangamati was selected purposively for the study. The criterion for selecting site was the availability of jhum cultivators. Information about jhum cultivators was collected from personal communication with concerned people and also own observation. During the study, a multistage sampling technique was adopted. Initially, from 10 upazillas in Rangamati districts, five upazillas were purposively selected for data collection. The name of selected upazillas are Juraichhari, Rangamati sadar, Kaptai, Belaichhari and Barkol. From each upazilla 11respondents were chose randomly for interview. A total 55 jhum cultivators were the ultimate sampling who was selected purposively from 5 upazillas.

\section{Preparation of survey schedule}

According to the objectives of the study a survey schedule was prepared to collect the expected data a from jhum cultivators. At first a draft schedule was prepared in accordance with the objectives of the study. Then the schedule was pre-tested to verify the relevance of the questions and the nature of the response of the sample procedures. After pre-testing and necessary adjustment, a final survey schedule was prepared for data collection.

\section{Selection of the respondents}

Eleven respondents were selected from each upazila. In total 55 respondents were selected for the survey. A detailed socio economic survey was conducted to assess educational status, age, sex, land status, present practices, occupation, income per annum of jhum cultivators and shifting (jhum) cultivation impacts on environment.

\section{Period of data collection}

For this study, the data were collected intensively by using structured survey schedules in recall method. The data collection covered period of three month starting from October to December, 2009. For this purpose the researcher paid a number of extensive visits himself throughout the period.

\section{Data collection process}

In order to fulfill the objectives of the study, relevant information and literature were collected from primary sources and secondary sources.

\section{Primary data collection}

The primary data has been collected by conducting a survey work with a well-prepared semi structured questionnaire. For this reason, interviewers were selected randomly. It is also done by physical visit to the jhum cultivation site and then interviewing the respondent. In it informal discussions with the participants and villagers of the target areas also included. The questions were asked in traditional language (Chakma) but written in English language.

\section{Secondary data collection}

The secondary sources of data including books, journals, various publications of government, institutions, and other organizations, articles of local and national newspapers and other research papers on same or similar issues have been used for data collection. In addition to this, internet has also been used as secondary source of data collection.

\section{Collection of photographs}

Five spots were studied during the field survey and from each spot photographs were collected by personal camera. In the studied area, the loss of top soil and other degradation situations were captured by photograph.

\section{Data processing and analysis}

A. The surveyed data were converted into frequencies and percentage forms. After collecting information from primary and secondary sources, data were processed and analyzed by following steps: Reviewed of collected data and information

b. Discarded of unnecessary parts of the information and data

c. Sorted of revised data and information

d. Analyzed for easy explanation

\section{Resutls and Discussion}

Status of the land use for jhum cultivation of the respondents in studied upazillas: 
In this field survey, 55 jhum cultivators were interviewed about the quantity of land only used for jhum cultivation in five upazillas of Rangamati district. In Barkal upazilla the jhum cultivators are using 42 acres of land for jhum cultivation. In Juraichhari upazilla 36 acres of land is being used for jhuming and the jhum cultivators in Bilaichhari upazilla are using 49 acres of land for jhum cultivation which is the highest amount of land used for jhuming in this district. The jhum cultivators of Kaptai upazilla are using 29 acres of land for jhum. The lowest amount of land used by jhum cultivators in Rangamati sadar upazilla and the amount is 24 acres. Total 180 acres of land is being used by jhum cultivation of five upazillas in Rangamati district.

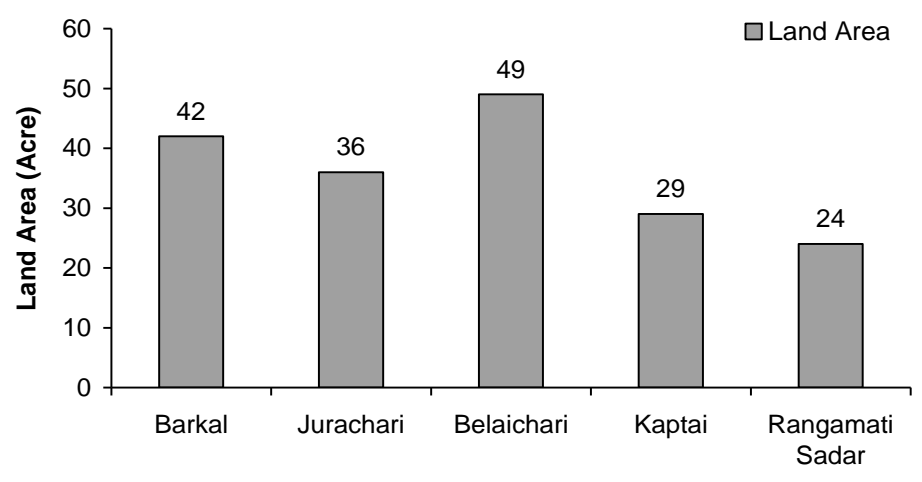

Name of upazilas

Fig. 1. Status of the land use for jhum cultivation of the respondents in studied upazillas

\section{Jhum cycle practices in shifting cultivation:}

Jhum cycle means the fallow period of shifting cultivation. In this study it was observed that in past period most of the cultivators $(67.27 \%)$ were practiced jhum cycle more than 6 years. About $29.09 \%$ and $3.64 \%$ respondents were practiced 4-6 years and $\leq 3$ years jhum cycle respectively. But in present situation $>6$ years jhum cycle practice is nil. Most of the respondents about $80.00 \%$ were said that they practiced fallow period $\leq 3$ years for shifting cultivation and the rest of the respondents said that they practiced 4-6 years of jhum cycle (Table 1).

Table 1. Duration of Jhum cycle practices for shifting (jhum) cultivation

\begin{tabular}{|c|l|c|c|}
\hline \multirow{2}{*}{ Period } & \multicolumn{1}{|c|}{ Range } & \multicolumn{2}{c|}{ Respondents } \\
\cline { 2 - 4 } & & 2 & 3.64 \\
\hline \multirow{3}{*}{ Past } & $\leq 3$ Years & 16 & 29.09 \\
\cline { 2 - 4 } & 4.6 Years & 37 & 67.27 \\
\cline { 2 - 4 } & $>6$ Years & 44 & 80.00 \\
\hline \multirow{3}{*}{ Present } & $\leq 3$ Years & 11 & 20.00 \\
\cline { 2 - 4 } & $4-6$ Years & - & - \\
\cline { 2 - 4 } & $>6$ Years & & \\
\hline
\end{tabular}

\section{Impact of Jhum cultivation on environment}

This study indicated that the environment of the studied area was degraded through jhum cultivation. Among the respondents maximum respondents (94.55\%) had given opinion that deforestation was the major environmental problem created by jhum cultivation (Table 2 \& Fig. 2). About $74.55 \%$ respondents had given opinion that shifting cultivation accelerated landslide (Fig. 3) and loss of top soil (Fig. 4). In this study $60.00 \%$ respondent had given opinion that lost of wild animals was occurring due to burn bushes and trees for Jhum cultivation (Fig.5) and also land degradation was occurred due to slash and burn practices (Fig. 6). In Table 2, 50.91\% respondents were responded that loss of bird species was also occurred due to jhum cultivation, $20.00 \%$ and $23.64 \%$ respondents opinion were decreased environmental balance and increased global temperature, respectively. Only $67.27 \%$ respondents were responded that jhum cultivation were created decrease crop yield (Table 2). 
Table 2. Impact on environment due to Jhum cultivation

\begin{tabular}{|l|c|c|c|}
\hline \multirow{2}{*}{ Types of impact } & \multicolumn{2}{|c|}{ Respondents } & \multirow{2}{*}{ Ranking } \\
\cline { 2 - 3 } & Number & $\%$ & 1 \\
\hline Loss of forest area (Deforestation) & 52 & 94.55 & 2 \\
\hline Loss of top soil & 41 & 74.55 & 4 \\
\hline Loss of wild animals & 33 & 60.00 & 5 \\
\hline Loss of bird species & 28 & 50.91 & 7 \\
\hline Decrease environmental balance & 11 & 20.00 & 6 \\
\hline Increase temperature & 13 & 23.64 & 3 \\
\hline Decrease crop yield & 37 & 67.27 & \\
\hline
\end{tabular}

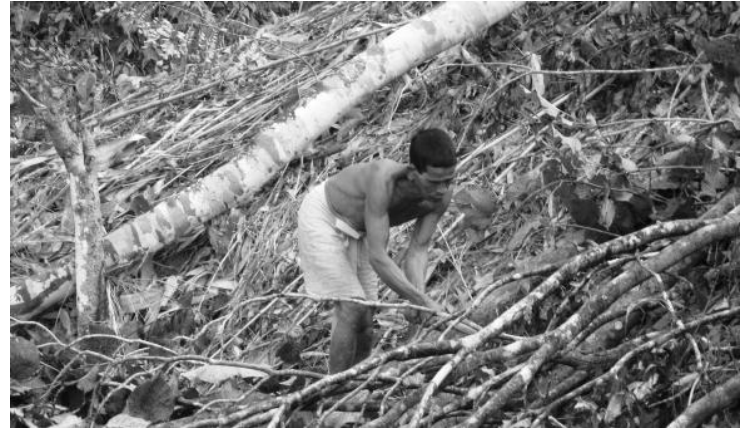

Fig. 2. Preparation of hill slopes for jhum cultivation by cutting bushes and trees.

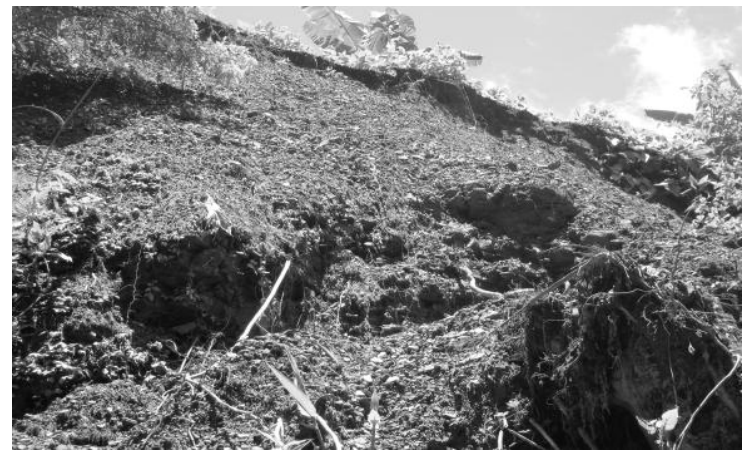

Fig. 3. Landslide was occurred due to Jhum cultivation

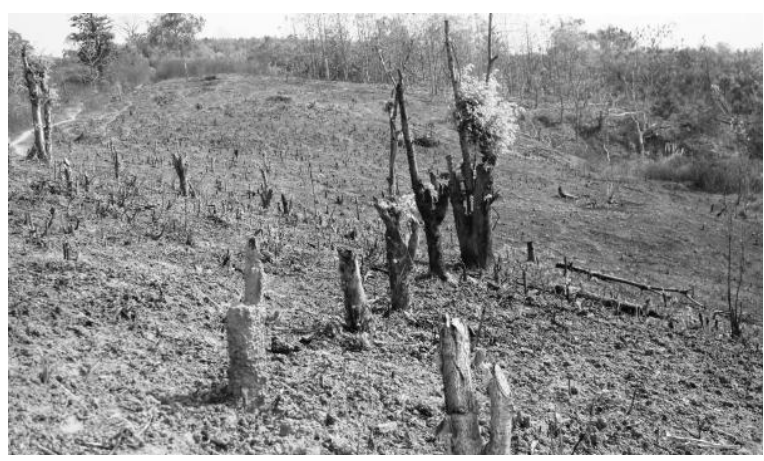

Fig. 4. Hill without forest cover vulnerable to losses of top soil

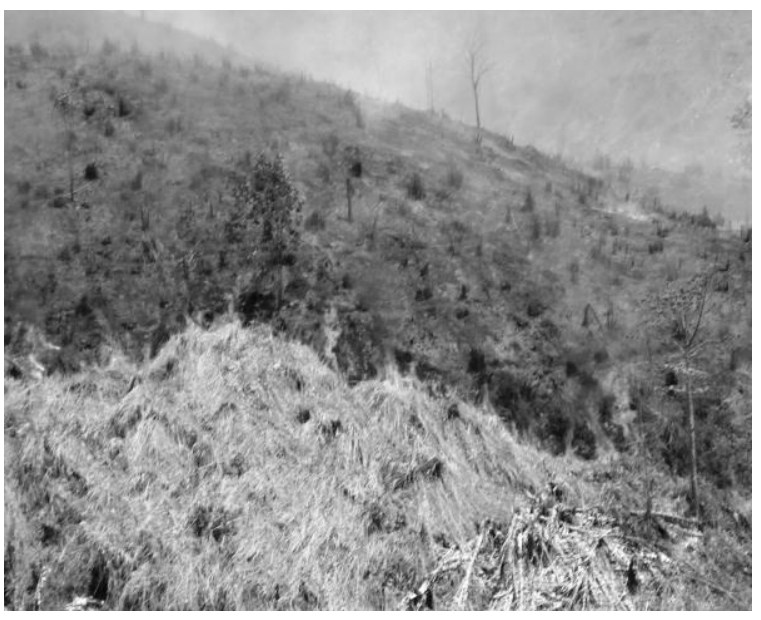

Fig. 5. Bushes and trees were burning for Jhum cultivation

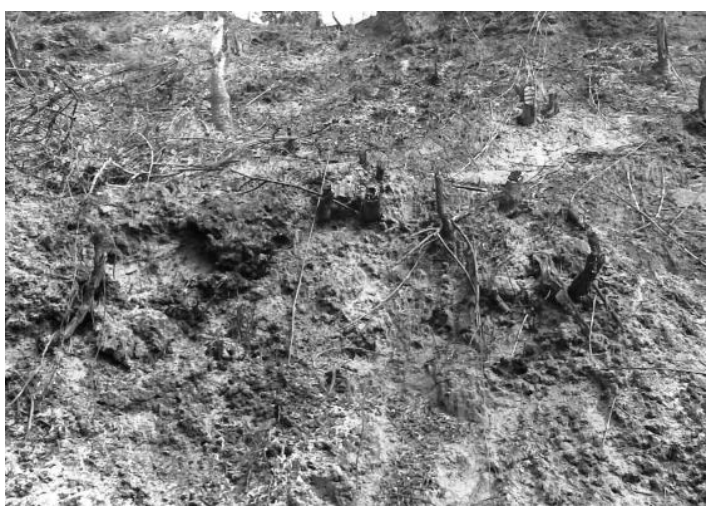

Fig. 6. Land degradation were occurred due to slash and burn practices (jhum)

\section{Nature of soil erosion due to jhum (shifting) cultivation}

According to the personal interview of people of the study area it was found that among the interviewees $38.18 \%$ peoples replied that the nature of soil erosion is high due to shifting cultivation practices. Similarly $45.45 \%$ and $16.36 \%$ peoples informed that the nature of soil erosion is medium and low respectively (Table $3)$. 
Table 3. Nature of soil erosion due to jhum (shifting) cultivation

\begin{tabular}{|l|c|c|c|}
\hline \multirow{2}{*}{ Rate of Erosion } & \multicolumn{2}{c|}{ Respondents } & \multirow{2}{*}{ Ranking } \\
\cline { 2 - 4 } & Number & 38.18 & 2 \\
\hline High & 21 & 45.45 & 1 \\
\hline Medium & 25 & 16.36 & 3 \\
\hline Low & 9 & & 2 \\
\hline
\end{tabular}

\section{Contributing Factors of environmental degradation:}

Population growth is considered by $90 \%$ of the respondents as a major factor causing severe degradation of environment in the study area. The effects of population on degradation of environment are considered moderate and insignificant by $9.7 \%$ and $0.2 \%$ of the respondents respectively. Besides population growth, deforestation and over use of natural resources are identified as causes of severe degradation by $82.1 \% 70.5 \%$ of the respondents respectively. Lack of knowledge / technologies and lack of proper planning are treated as severe cause of degradation by $54 \%$ and $52 \%$ of the respondents respectively. Jhum cultivation is viewed as a severe cause by $38 \%$ and a moderate cause by $46.6 \%$ and an insignificant cause of degradation of environment by $15.4 \%$ of the respondents under survey. Lack of alterative livelihood is identified by $44.2 \%$ as a severe cause, by $40.4 \%$ as a moderate cause and by $15.4 \%$ as insignificant causes of degradation of environment.

The effects of water pollution and forest fire are considered severe by less than $50 \%$ of the respondents. Use of fertilizers/pesticides cause severe degradation of environment by opined $21.9 \%$ of the respondents. In addition cutting of hill, collection of soil, extraction of stone, river erosion and land slide as responsible for degradation of environment (Table 4).

Table. 4. Contributing factors for degradation of environment as perceived by the Jhum cultivators

\begin{tabular}{|c|c|c|c|c|}
\hline \multirow{3}{*}{ Factors } & \multicolumn{4}{|c|}{$\%$ of the Respondents } \\
\hline & \multicolumn{4}{|c|}{ Extent of Degradation } \\
\hline & Severe & Moderate & Insignificant & Total \\
\hline Population growth & 90.1 & 9.7 & 0.2 & 100 \\
\hline Deforestation & 82.1 & 17.7 & 0.2 & 100 \\
\hline $\begin{array}{l}\text { Jhum cultivation/Shortening of fallow } \\
\text { period }\end{array}$ & 38.0 & 46.6 & 15.4 & 100 \\
\hline Over use of natural resources & 70.5 & 21.8 & 7.7 & 100 \\
\hline Use of fertilizers/pesticides & 21.9 & 63.4 & 14.7 & 100 \\
\hline $\begin{array}{l}\text { Lack of alternative livelihood } \\
\text { opportunities }\end{array}$ & 44.2 & 40.4 & 15.4 & 100 \\
\hline Lack of knowledge/technologies & 54.0 & 36.0 & 10.0 & 100 \\
\hline Lack of proper planning & 51.8 & 39.7 & 8.5 & 100 \\
\hline Forest fire & 47.2 & 38.4 & 14.4 & 100 \\
\hline Water pollution & 44.2 & 50.8 & 5.0 & 100 \\
\hline Monoculture plantation & 26.4 & 50.6 & 23.0 & 100 \\
\hline
\end{tabular}

\section{Shifting cultivation as a controversial practices}

According to the opinion of the respondents were responded that $85.45 \%$ of the respondents had given the opinion that deforestation was occurring mainly for shifting cultivation. It was top ranked against other controversial practices. The second highest ranked loss of biodiversity (69.09\%) was occurring for shifting cultivation. 
Table 5. Opinion of respondents that Jhum cultivation as a controversial practice

\begin{tabular}{|l|c|c|c|}
\hline \multicolumn{1}{|c|}{ Items } & \multicolumn{2}{c|}{ Respondents } & \multirow{2}{*}{ Ranking } \\
\cline { 2 - 4 } & Number & 85.45 & 1 \\
\hline Deforestation & 47 & 69.09 & 2 \\
\hline Loss of biodiversity & 38 & 67.27 & 3 \\
\hline Hilly area cultivation & 37 & 60.00 & 4 \\
\hline Old method of cultivation & 33 & \multirow{2}{*}{4} \\
\hline
\end{tabular}

\section{Conclusion}

The arresting or eradicating of shifting cultivation had been underway since the start of the 20th Century. After Independence, jhum control programmes started in earnest. However, it was soon realized that cash crop cultivation couldn't be adopted as an alternative to jhuming which people practice mainly to meet their essential food requirement. The agroecological systems of the CHT have led to a shift in emphasis in recent years from jhum control to jhum management, more specifically, to the management of fallows. The Government of Bangladesh pioneered agro-forestry interventions in jhum farming cycles. The environment in the Chittagong Hill Tracts (CHT) is under pressure. Demographic and environmental conditions are changing. Jhum cultivation is becoming unsustainable. This, combined with other factors such as forest over exploitation, is the cause of increased land degradation, such as soil erosion, nutrient decline, and decreased biodiversity. Information on the status of the environment is required for the formulation of alternative strategies for sustainable management. The pressures on the environment and the causative factors and processes must be analyzed. New methods must be developed, applied, and tested for sustainable management of jhum cultivation.

\section{Referances:}

BBS (Bangladesh Bureau of Statistics). 2001. Population census wing based on preliminary results.

Borggaarrd, O. K.; Gafur, A. and Petersen, L. 2003. Sustainability appraisal of shifting cultivation in the Chittagong Hill Tracts of Bangladesh. Ambio 32(2): 118-123.

Dasgupta, S. and Ahmed, F. U. 1998. Natural resource management by tribal community: a case study of Bangladesh. p. 52-55.

Dewan, T. 2008. Jumchas (Jhum Cultivation).

Gafur, A.; Jensen, J. R.; Borggaard, O. K. and Petersen, L. 2003. Runoff and losses of soil and nutrients from small watersheds under shifting cultivation (jhum) in Chittagong

Tripura, P. and Harun, A. 2003. Parbotto Chattagrame Jumchash. 